International Journal of Physical Modelling in Geotechnics

Physical modelling of air injection to remediate liquefaction

Zeybek and Madabhushi

\title{
Physical modelling of air injection to remediate liquefaction
}

\author{
Abdulhakim Zeybek MSC \\ PhD Candidate, Department of Engineering, Schofield Centre, \\ University of Cambridge, Cambridge, UK (corresponding author: \\ az323@cam.ac.uk)
}

\author{
Gopal Santana Phani Madabhushi MTech, PhD (Cantab) \\ Professor of Civil Engineering, Department of Engineering, \\ University of Cambridge, Cambridge, UK
}

Seismic liquefaction of loosely packed, saturated soils poses a significant threat to the built environment. Recently, air injection into liquefiable soil deposits has been introduced as an innovative and cost-effective liquefaction mitigation technique. However, few effective guidelines are available to the engineers for its application and performance. The way that air should be injected appropriately, most particularly, in the presence of structures, is not clearly defined. The distribution of retained air bubbles within the saturated soil medium and its effect on the seismic response also need further investigation. In an effort to offer insights into this problem, an experimental programme consisting of a series of centrifuge and $1 \mathrm{~g}$ shaking table tests was undertaken. The results have shown that the use of higher air injection pressure provides a much wider and a more uniform air-entrapped zone, but increases the risk of soil deformations developed under the foundations. The distance from the air injector and preferential flow pathways influence the distribution of the retained air bubbles and seismic response of the soil models. Moreover, it was shown in a novel way that the air injection technique is not very effective at low confining stresses to reduce liquefaction-induced deformations beneath shallow foundations.

\begin{tabular}{|c|c|}
\hline \multicolumn{2}{|c|}{ Notation } \\
\hline$D_{\mathrm{r}}$ & relative density \\
\hline$d_{10}$ & grain diameter at $10 \%$ passing \\
\hline$d_{50}$ & grain diameter at $50 \%$ passing \\
\hline$e_{\max }$ & maximum void ratio \\
\hline$e_{\min }$ & minimum void ratio \\
\hline$G_{\mathrm{s}}$ & specific gravity \\
\hline$g$ & acceleration of gravity \\
\hline$H_{\mathrm{s}}$ & height of soil \\
\hline$n$ & porosity \\
\hline$P_{\text {hyd }}$ & hydrostatic pressure \\
\hline$\left(P_{\text {inj }}\right)_{\max }$ & maximum injection pressure \\
\hline$\left(P_{\text {inj }}\right)_{\min }$ & minimum injection pressure \\
\hline$\left(P_{\text {inj }}\right)_{\text {net }}$ & net injection pressure \\
\hline$q$ & bearing pressure \\
\hline$r_{\mathrm{u}}$ & excess pore pressure ratio \\
\hline$S_{\mathrm{r}}$ & degree of saturation \\
\hline$S_{\mathrm{rO}}$ & initial degree of saturation \\
\hline$\left(T_{\text {inj }}\right)_{\text {net }}$ & net air injection period \\
\hline$U_{\mathrm{c}}$ & uniformity coefficient \\
\hline$\gamma$ & shear strain \\
\hline$\Delta h$ & change in the fluid level \\
\hline$\sigma_{\mathrm{v}}^{\prime}$ & vertical effective stress \\
\hline$\tau$ & shear stress \\
\hline
\end{tabular}

\section{Introduction}

Seismically induced liquefaction of soils has repeatedly caused significant damage to the geotechnical structures. Over the decades, several liquefaction remediation techniques have been developed to reduce or eliminate the liquefaction risk and the associated structural damage. Most of these techniques are however expensive due to the installation costs. Furthermore, the application of these techniques to the existing structures is often limited. In recent years, a number of studies have focused on the development of innovative and cost-effective liquefaction remediation techniques that can be used for the new and particularly for the existing structures. A few researchers have looked into the feasibility of techniques which involve artificial formation of gas bubbles within the liquefiable soil deposits, leading to a reduction in the degree of saturation, $S_{\mathrm{r}}$ and an increase in the liquefaction resistance of soil. Air injection, among these techniques, can be more attractive for the researchers and engineers due to its applicability in the field (Okamura et al., 2011), its cost-effectiveness and due to it being an eco-friendly liquefaction mitigation method (Okamura and Tomida, 2015).

Zeybek and Madabhushi (2017b) have investigated in a quantitative manner the most critical liquefaction-induced deformation mechanisms and their subsequent contributions to the overall foundation settlements for the saturated and airinjected partially saturated soils. It was found that unlike the saturated soil the deviatoric type of deformations under the static and dynamic stresses were significantly minimised by the air injection. The depth of liquefaction also markedly reduced, and a complete bearing failure mechanism under the shallow foundation did not form, leading to significantly smaller foundation settlements. Moreover, it was exclusively shown by Zeybek and Madabhushi (2017a) that the deformation 
mechanisms, generation of excess pore pressures and consequent liquefaction-induced settlements of shallow foundations were a strong function of the degree of saturation of airinjected soils.

Seed et al. (2003) have stated that the selection and implementation of liquefaction mitigation techniques require a thorough evaluation of the important parameters: (a) applicability, (b) effectiveness, $(c)$ verifiability of the reliability of the mitigation achieved, $(d)$ cost and $(e)$ other sources of concern (e.g. environmental issues). The environmental impact and cost are of less significance for the air injection technique since the only material used is the air, and the execution cost is low. The applicability and effectiveness of liquefaction remediation methods can be assessed based on the field and experimental data. The above experimental findings strongly suggest that air injection into the liquefiable soils can markedly minimise the liquefaction risk, and this technique holds promise for use as a liquefaction mitigation measure. However, the main concerns are the appropriate application of this technique in the presence of structures and its reliability over a sufficient period of time. Few experimental research programmes and in situ tests were conducted regarding the relevant topics. Okamura et al. (2006) have investigated the sustainability of the retained air bubbles within the in situ soil deposits, and concluded that they can remain entrapped in soils for a long time. Moreover, the longevity of the air bubbles under various conditions was experimentally studied by Yegian et al. (2007). The results have showed that the trapped air bubbles do not dissipate, diffuse or escape from the soil easily. The partially saturated condition, for instance, was sustained for a period of $442 \mathrm{~d}$, at least under hydrostatic conditions. The change in the degree of saturation was only $1.8 \%$ over this period. These findings indicate that this technique can be reliable, if properly applied in the field. The evaluation of the zone of influence (effectively desaturated zone) was also studied through laboratory and field tests (Okamura et al., 2011; Yasuhara et al., 2008).

The research reported in this paper investigated in a quantitative manner the way that air injection should be performed beneath shallow foundations. Another objective of the study was to demonstrate whether the liquefiable soil can be homogeneously desaturated and to what extent the air-entrapped zone affects the seismic behaviour of soils and foundations. Eventually, the effect of confining stress on the performance of air injection technique was investigated at $1 g$ and at higher centrifugal accelerations. The main intent of this paper is to reinforce and build on the previous research by performing new $1 \mathrm{~g}$ small-scale tests and centrifuge tests. The findings presented herein may pave the way for engineers to use this particular technique in practice more confidently and more often.

\section{Physical modelling of air injection}

To study air injection as a liquefaction mitigation measure beneath shallow foundations, it would be ideal to use field data. However, the actual and useful field data on this phenomenon are quite rare since acquiring them is an extremely challenging and expensive task. Therefore, it is of necessity to use some physical modelling techniques in the laboratory. In this research, geotechnical centrifuge experiments and $1 \boldsymbol{g}$ shaking table tests were performed. A summary of the testing programme is shown in Table 1 .

\subsection{Geotechnical centrifuge tests}

A series of centrifuge experiments were performed on the Turner beam centrifuge at the Schofield Centre of Cambridge University. Centrifuge models were prepared and spun at a nominal centrifugal acceleration of $70 \mathrm{~g}$. Unless otherwise indicated, all units presented in this paper are in prototype scale (PS). The shallow foundation used in the tests was a strip foundation exerting a bearing pressure, $q$ of $50 \mathrm{kPa}$ and with a width of $3.5 \mathrm{~m}$. The liquefiable layers of loose soil $\left(D_{\mathrm{r}} \sim 40 \%\right)$ were prepared in a rigid, Perspex window by the air pluviation technique. It is noted that layers of Duxseal were used at the container end walls to minimise the impact of the rigid boundaries (Steedman and Madabhushi, 1991). The soil used in the tests was Hostun HN31 sand $\left(d_{10}=0.315 \mathrm{~mm}\right.$, $d_{50}=0.480 \mathrm{~mm}, U_{\mathrm{c}}=1.67, e_{\min }=0.555, e_{\max }=1.01, G_{\mathrm{s}}=2.65$ and air entry value (AEV) of $1.3 \mathrm{kPa}$ ). The instrumentation used included arrays of miniature pore pressure transducers (PPTs), piezoelectric and microelectromechanical system accelerometers and linear variable differential transducers. A high viscous aqueous solution of hydroxypropyl methylcellulose (viscosity of $70 \mathrm{cSt}$ ) was used during the saturation of models. This was necessary to overcome the inconsistency between the scaling laws of dynamic and seepage time (Schofield, 1981). The degree of saturation of models was determined based on the conventional mass and volume method, and the computed degrees of saturation at the end of the saturation process were consistently more than $99 \%$.

Digital images were attained using a high frame-rate camera. Particle image velocimetry analysis was performed on the images to obtain the soil deformations beneath the shallow foundation (White et al., 2003). A stored angular momentum actuator device (Madabhushi et al., 1998) was utilised to generate sinusoidal pseudo-harmonic input motions. The excitations were parallel to the long side of models. The peak input acceleration, frequency and duration of the shakings were generally $0 \cdot 18 \mathrm{~g}, 0.72 \mathrm{~Hz}$ and $28 \mathrm{~s}$ in PS, respectively.

For the application of air injection, a rubber air curtain hose, typically used for fish tanks, was placed at the bottom of soil models. This air bubble curtain had several tiny openings of 


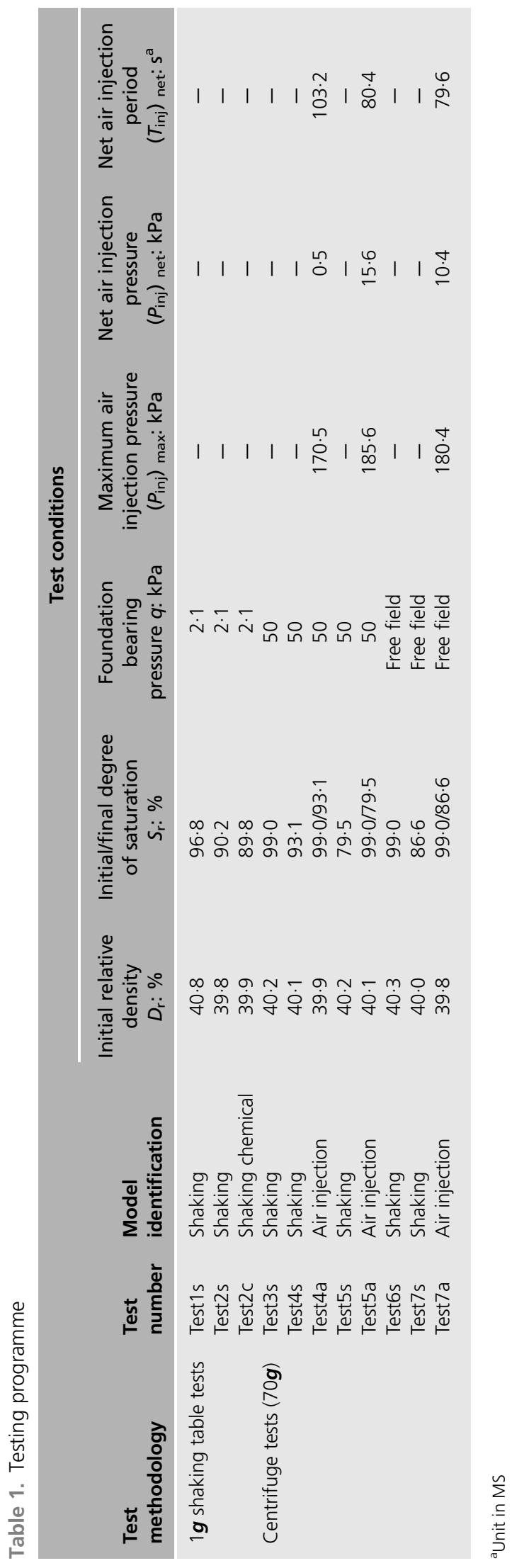

about $0.5 \mathrm{~mm}$ diameter and $5 \mathrm{~mm}$ spacing in model scale (MS). The schematic cross-section of the centrifuge models is given in Figure 1.

\subsection{9 shaking table tests}

A series of shaking table tests were carried out in this study to gain some qualitative information on the air injection technique. The images were obtained throughout the tests using the high-speed camera. During the tests, $1 \boldsymbol{g}$ shaking table at the Schofield Centre was used to fire the earthquakes. The shaking table has a motor which stores angular momentum in a flywheel. This is then converted into the horizontal shaking through a crank. It generates nearly sinusoidal motion at a single frequency.

An example for the arrangement of the shaking table and soil model is illustrated in Figure 2. A model foundation with a full length of the model box $(300 \mathrm{~mm}), 50 \mathrm{~mm}$ wide and $30 \mathrm{~mm}$ high was used in the shaking table tests. The bearing pressure exerted by the model foundation was $2 \cdot 1 \mathrm{kPa}$. Shaking table models were essentially prepared in the same way as the centrifuge models in a model container with a clear Perspex viewing front. Loose sand models at a relative density of about $40 \%$ were saturated very slowly by applying a gravity head and infiltrating the de-aired water from the base.

It is worth noting that for a comparison, a third shaking table test was conducted. In this test, small and uniformly distributed oxygen bubbles were created across the soil through the reaction between the chemical compound sodium perborate monohydrate and water. This compound was found in a tablet form (efferdent). Prior to the sand pouring, the powdered efferdent was mixed with dry sand at predetermined proportions. The prepared mixture was dry pluviated and then saturated with water, as explained before. The reaction of the chemical with water $(1 \mathrm{~d})$ created oxygen bubbles inside the soil, displacing the pore water upwards. More details about this technique were given by Gokyer (2009).

In all of the shaking table tests, the applied peak base acceleration was $\sim 0 \cdot 18 \mathrm{~g}$, and the schematic cross-section of the models was as given in Figure 3.

\section{Effective application of air injection}

The effective use of the air injection technique in design practice may require a thorough understanding of the magnitudes, rates and distribution of applied air injection. The results from the centrifuge tests are expected to shed light on this problem.

\subsection{Air injection pressure}

In the air injection phase of the centrifuge tests, air was supplied into the soil through the air bubble curtain located 


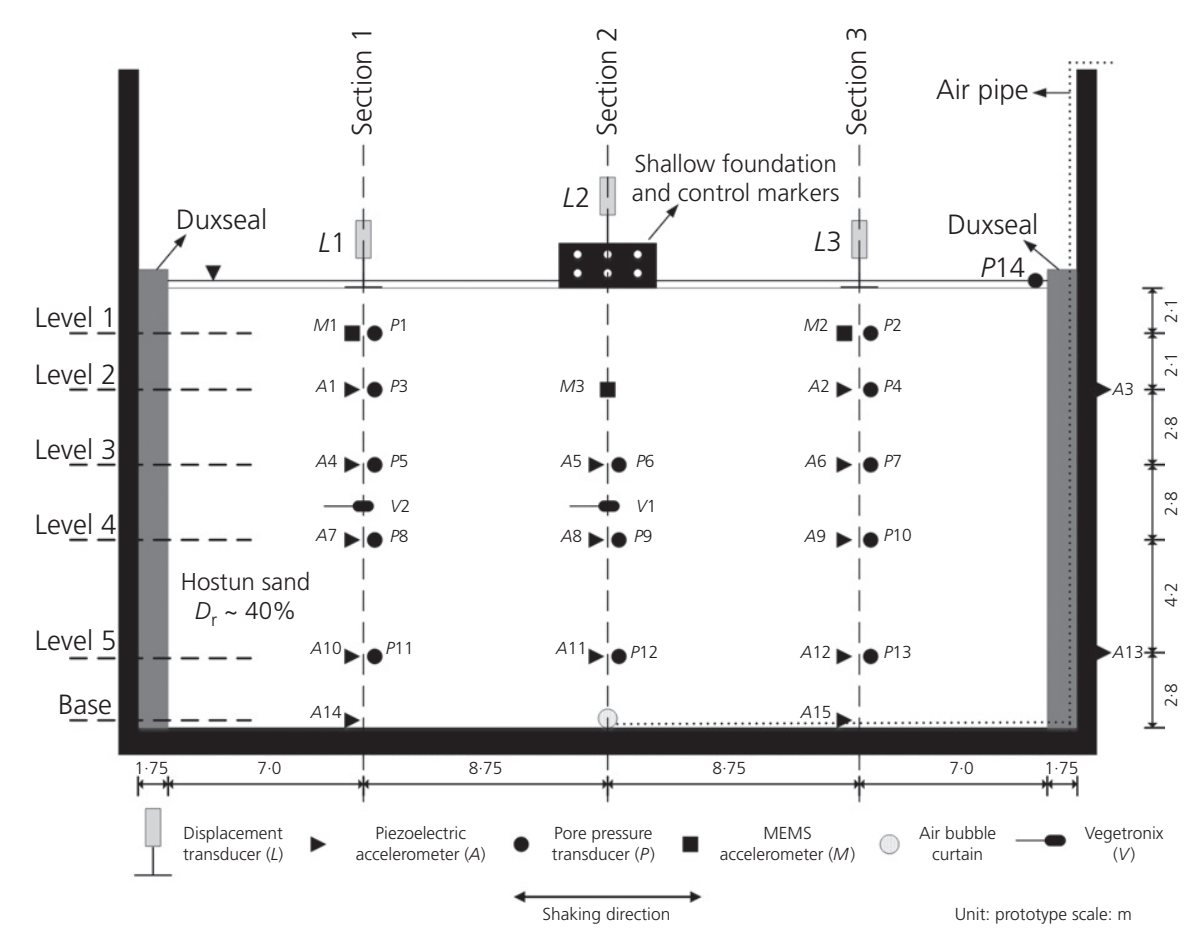

Figure 1. Model layout for the centrifuge tests

on the centre bottom of the model. This air curtain extended along the plain strain direction and represented a two-dimensional air flow condition. The air pressures were measured right before the air curtain. Figure 4 presents typical examples of pressure-time and degree of saturation-time histories obtained during the air injection process. It is apparent that air bubbles can be entrapped in saturated specimens only when the air pressure reached the sum of hydrostatic pressure, $P_{\text {hyd }}$ at the injection point and AEV of soil. The pressure required to initiate air flow in the saturated medium refers to the minimum air injection pressure, $\left(P_{\mathrm{inj}}\right)_{\min }$. The time period between the initiation of air flow in soil and its end indicates the net air injection period, $\left(T_{\mathrm{inj}}\right)_{\text {net }}$. The PPT installed above the ground level (P14) continuously provided data on the evaluation of fluid level. As seen, the fluid level and therefore the pore fluid pressure increased due to the volume of entrapped air bubbles in soil. The change in the average $S_{\mathrm{r}}$ of soils across the model ground with time was simply evaluated using the soil phase relationships and the following equation

1. $S_{\mathrm{r}}(t)=S_{\mathrm{r} 0}-\frac{\Delta h(t)}{H_{\mathrm{s}} n}$

where $S_{\mathrm{r} 0}, \Delta h, H_{\mathrm{s}}$ and $n$ are the initial degree of saturation, change in the fluid level, height of soil and porosity, respectively. It is evident from Figure 4 that the final volume of air bubbles trapped in soil is a function of air pressure. The final average $S_{\mathrm{r}}$ decreases with increasing air injection pressure.

Although augmentation in the air injection pressure can be seen as an effective way of maintaining an extra reduction in $S_{\mathrm{r}}$ and hence an increase in the liquefaction resistance of soils, the engineers may need to approach this with scepticism, particularly in the event of air injection beneath foundations of existing structures. The excessive air pressure might disturb the soil structure and cause cracking and fissuring, particularly near the air injection point. An example of the excessive settlement of shallow foundation $(0 \cdot 18 \mathrm{~m}$ in PS) during the air injection process was experimentally shown by Zeybek and Madabhushi (2017b).

Ogata and Okamura (2006) postulated the theoretical maximum air pressure above which soil can be disturbed, as given by the following equation

2. $\left(P_{\text {inj }}\right)_{\max }=P_{\text {hyd }}+0 \cdot 5 \sigma_{\mathrm{v}}^{\prime}$

where $\left(P_{\text {inj }}\right)_{\max }, P_{\text {hyd }}$ and $\sigma_{\mathrm{v}}^{\prime}$ represent the maximum air injection pressure, hydrostatic pressure and vertical effective stress at the injection point, respectively. As already shown in Figure 4, the maximum applied pressure was kept almost same as the $\left(P_{\text {inj }}\right)_{\min }$ in Test4a. This caused a foundation settlement of 

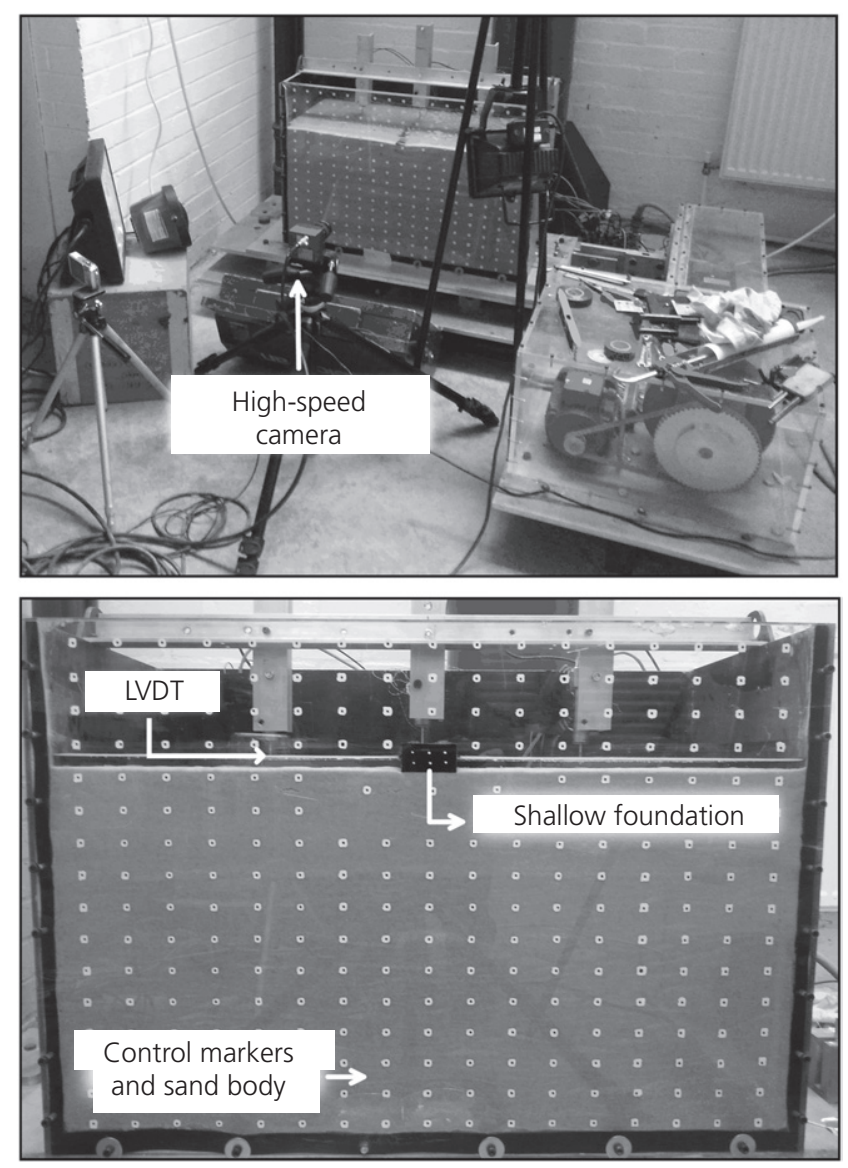

Figure 2. $1 \boldsymbol{g}$ shaking table test set-up

$9.6 \mathrm{~mm}$ in PS. Figure 5 shows typical examples of soil deformations and displacements that developed beneath the shallow foundation (Test5a) and in the free field (Test7a) during air injection. In Test7a, the maximum injection pressure was equal to the sum of the hydrostatic pressure and $\sim 0 \cdot 1$ times of the vertical effective stress at the injection point. This led to vertical downward displacements in the free field and an average settlement of $15 \mathrm{~mm}$ in the PS. With a maximum air injection pressure of about $0 \cdot 12$ times of $\sigma_{\mathrm{v}}^{\prime}$, the foundation settled $\sim 21 \mathrm{~mm}$ in the PS in Test5a. It can be observed that air-induced settlements were inevitable, irrespective of the air injection pressure. This was due to the compressible nature of air-injected partially saturated soils and effective stress drop during the air flow (Zeybek and Madabhushi, 2017b). However, based on the findings presented herein and observations made during the tests, it may be suggested that the magnitude of air-induced settlements can be notably minimised if

a well-controlled process throughout the experiments (e.g. increasing the air pressure in a controlled manner and close monitoring of foundation response) is maintained.
Gradual application of air injection is proven to be a necessary step towards limiting the possible foundation settlements

- the applied net air injection pressure, $\left(P_{\text {inj }}\right)_{\text {net }}$ given in Equation 3 is kept smaller (ideally maximum $10 \%$ of $\sigma_{\mathrm{v}}^{\prime}$ such as in Test5a).

3. $\left(P_{\text {inj }}\right)_{\text {net }}=\left(P_{\text {inj }}\right)_{\max }-\left(P_{\text {inj }}\right)_{\min } \leq 0 \cdot 1 \sigma_{\mathrm{v}}^{\prime}$

The air-induced settlements can remain within the acceptable limits for a real structure in the field in the case of smaller net air pressure applied. However, applying smaller air pressure may exert impacts on the area and distribution of partially saturated zones. This is examined in the following section.

\subsection{Distribution of air bubbles}

The injection of air into the saturated soils was observed to alter the colour of soils. The colour of the air-entrapped zones was much brighter compared with the nearly fully saturated zones, and this was clearly visible in the front window. Twodimensional digital images were taken and processed with the image processing toolbox of MATLAB. Figure 6 addresses the distribution of air bubbles in the partially saturated soil models, approximately defined based on the colour change. The approximate zone of influence or effective air-entrapped zone is illustrated by the broken curves. The actual position of the air injector is also shown. It is apparent that prior to air injection the colour of the saturated soil was all dark in Test7a(b), whereas some brighter coloured soils became visible following a $79.6 \mathrm{~s}$ (MS) of net air injection in Test7a(a). It is obvious that the colour of the soil varied within the zone of influence. This indicates that the air bubbles were retained erratically, and the partial saturation was not completely uniform, even within this zone. The duration of net air injection was $103 \cdot 2$ and $80 \cdot 4 \mathrm{~s}$ (MS) in Test4a and Test5a, respectively. A comparison between these two tests shows that the degree of saturation was reduced more, and a much wider air-entrapped zone was accomplished in Test5a. Furthermore, air bubbles were more uniformly and homogeneously distributed within the soil in Test5a. The different observations in the tests are attributable to the air injection pressure and preferential flow paths in the saturated medium. It was found that the higher the air injection pressure, the wider and more uniform the effective air-entrapped zone that was attained, which is well consistent with the laboratory data from Yasuhara et al. (2008). With a smaller net air injection pressure, it was however found very difficult to achieve uniformly distributed air-entrapped zones. The injected air bubbles had a tendency to flow through the surface along a path of less restriction (preferential flow pathways), particularly in Test7a(a). 


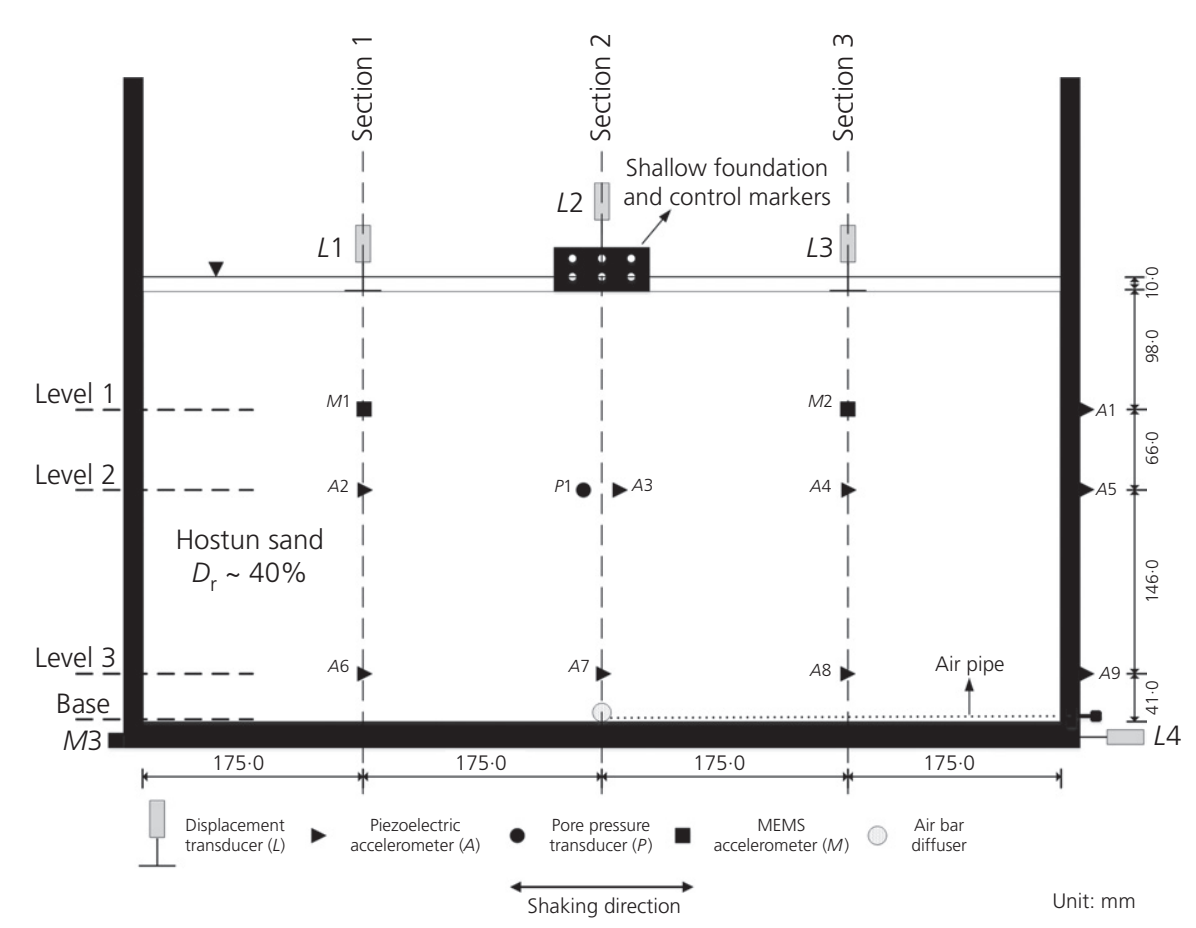

Figure 3. Model layout for the shaking table tests (MS)
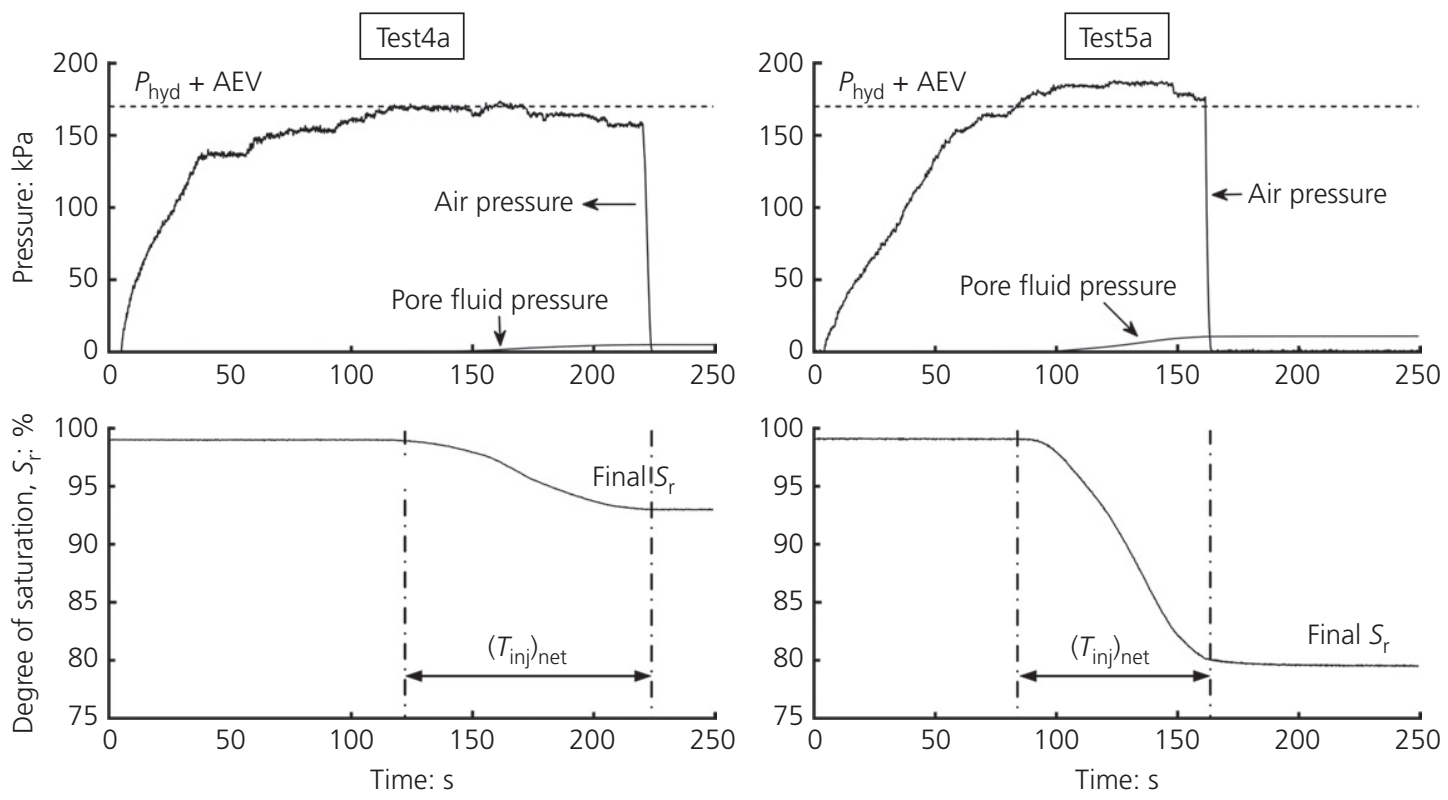

Figure 4. Typical pressure-time and degree of saturation-time histories during the air injection process (MS) 

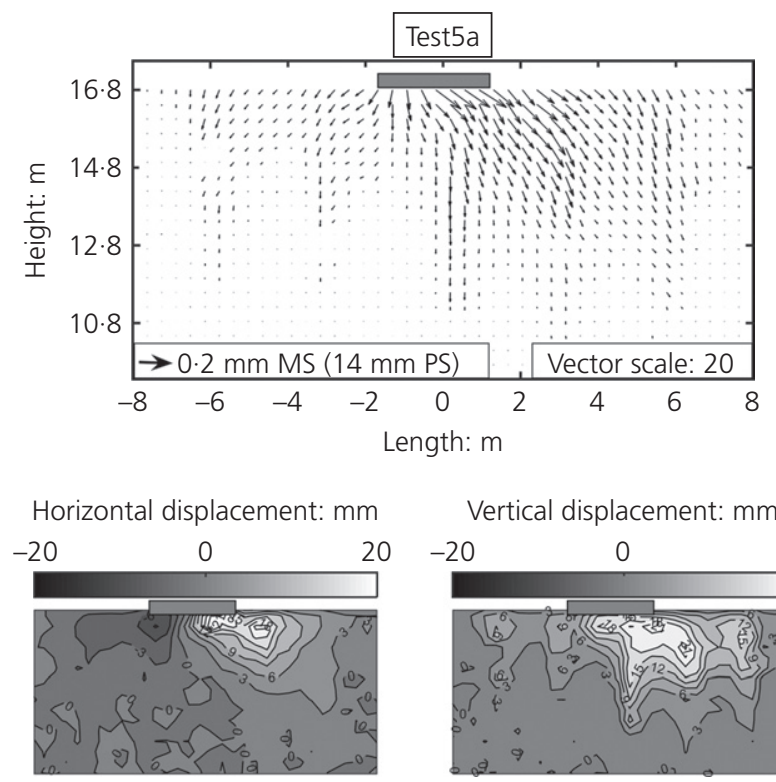

Vertical displacement: $\mathrm{mm}$

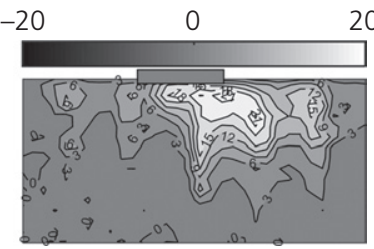

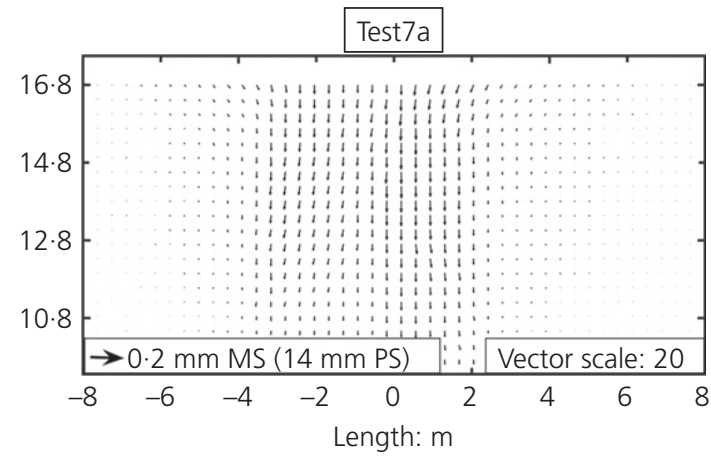

Horizontal displacement: $\mathrm{mm}$ Vertical displacement: $\mathrm{mm}$

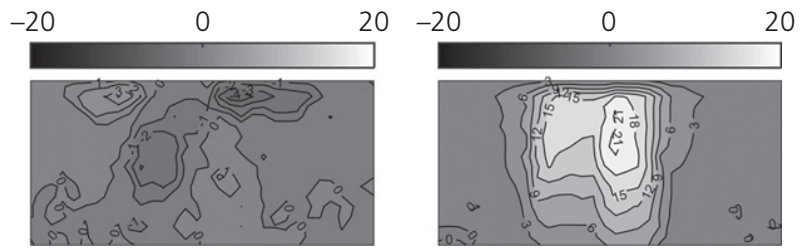

\section{Effective performance of air injection}

\subsection{Impacts of distribution and magnitude of $S_{r}$ on the seismic response}

The non-uniform distribution of retained air bubbles and narrower zone of influence might potentially have some implications for the seismic response of soil. To investigate this, the variation of excess pore pressure ratios, $r_{\mathrm{u}}$ with distance from the air injector is shown in Figure 7. The $r_{\mathrm{u}}$ is the ratio of maximum excess pore pressure generated during the earthquake to the initial vertical effective stress calculated without considering the foundation-induced stresses. As evident from the figure, air injection significantly increased the resistance of soil to pore pressure generation. Compared with the nearly fully saturated soil with no air injection (Test6s), much smaller excess pore pressures developed in the partially saturated soils (Test $4 \mathrm{~s}, 5 \mathrm{~s}, 7 \mathrm{~s})$. The more the reduction in $S_{\mathrm{r}}$, the less the $r_{\mathrm{u}}$ values that were observed. However, the efficacy of air injection to reduce $r_{\mathrm{u}}$ decreases with radial distance from the air injection point. The liquefaction resistance of soils seems to vary at discrete points of soil due to the non-uniformity of desaturation. It is noted that the excess pore pressure ratios at some layers were more than unity $\left(r_{\mathrm{u}}>1\right)$. This was attributed to the large dilation and contraction cycles due to the cyclic shearing in these layers. This caused an increase and a decrease in excess pore pressures in each cycle. The $r_{\mathrm{u}}$ values were calculated based on the peak values of excess pore pressure cycles which were larger than the effective stresses at the corresponding depths. Moreover, the foundation-induced stresses were not accounted for when calculating the effective stresses since the true stress distribution in the liquefiable soils, especially during significant soil softening, was difficult to be determined. This might also contribute to the larger values of $r_{\mathrm{u}}$.

The evaluations of the variation of excess pore pressures with time and depth are depicted in Figure 8. The total head isochrones show the direction and magnitude of the hydraulic gradients (slope of the isochrones) formed at different times. It is remarkable that in Test6s and Test7s, the excess pore pressure profile touch or nearly touch the $r_{\mathrm{u}}=1$ line at $4 \mathrm{~m}$ soil depth, independent of the initial $S_{\mathrm{r}}$. This indicates that at least $4 \mathrm{~m}$ of soil deposit was liquefiable in both tests. However, soil softening due to excess pore pressure generation below $4 \mathrm{~m}$ soil depth was notably smaller in Test7s, when compared with its counterpart. This shows that there is a limiting soil depth where the positive impact of air injection became negligible, particularly at shallow depths. This can be attributed to the proximity to the drainage boundary and to the low confining stresses at these layers, which is examined in the next section. The figure also shows that the dissipation behaviour in the soils is different depending on the presence of air bubbles. After the shaking ceased, the flow of pore fluid was generally vertically upwards in all locations in Test6s. However, the pore fluid flowed upwards and downwards depending on the time and depth in Test7s. The complex dissipation behaviour in this test was attributed to the non-uniform distribution of air bubbles within the soil specimens.

\subsection{Impacts of confining stress on seismic response}

In this phase of the research, the impacts of confining stress on the efficacy of air injection to reduce liquefaction hazards 

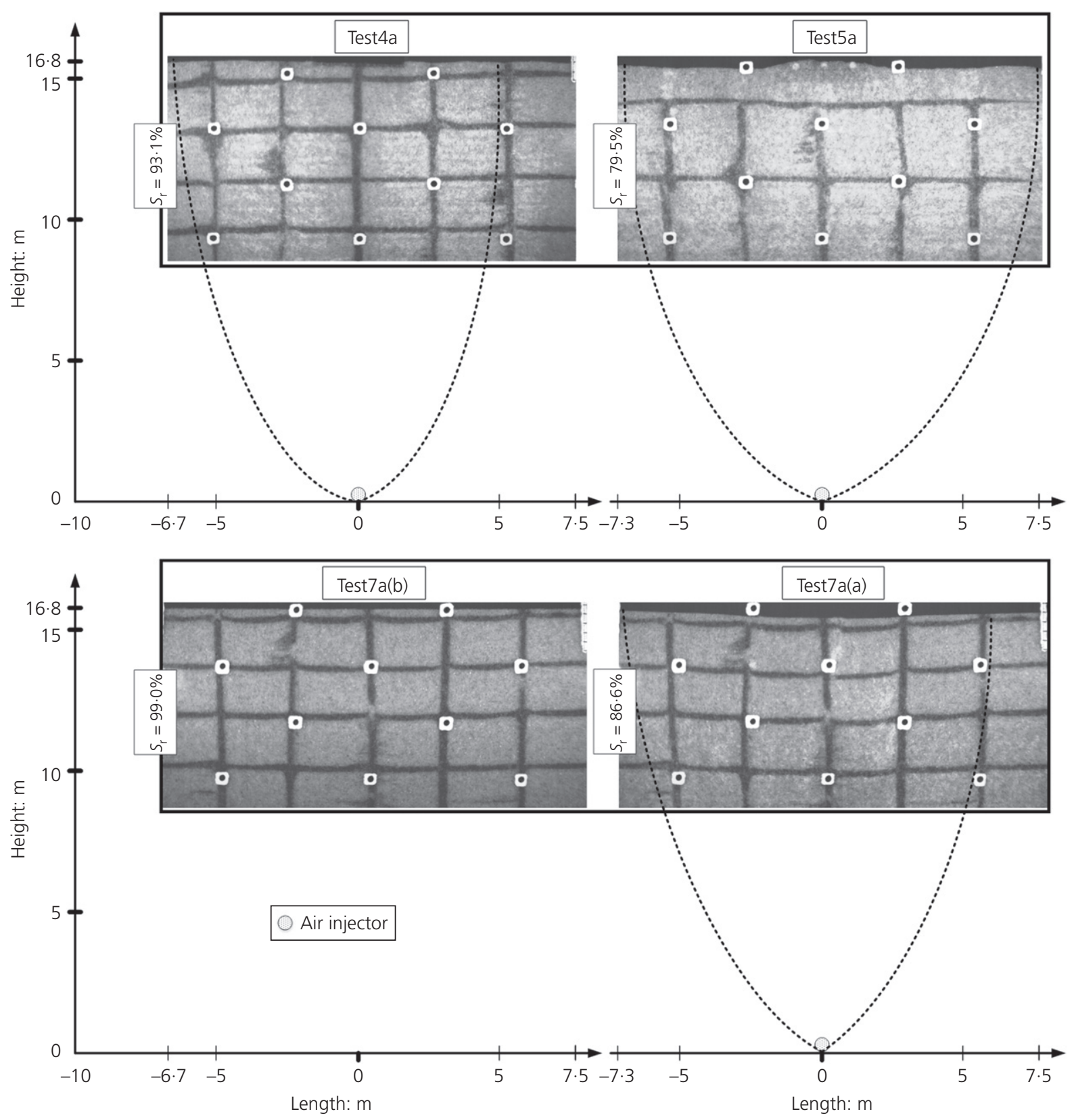

Figure 6. Approximate effective air-entrapped zones

beneath shallow foundations was investigated in a novel way through a suit of $1 \boldsymbol{g}$ shaking table and geotechnical centrifuge tests. The influence of confining stress on the shear stressstrain response was also studied.

The deformation mechanisms and displacements developed during the $1 \boldsymbol{g}$ shaking table experiments are shown in Figure 9. In Test1s (with no air injection), a very deep layer of liquefaction occurred, and the foundation settled significantly $(27 \mathrm{~mm})$. The soil under the footing moved vertically, and the soil under the edges of the foundation had a tendency to displace laterally. In fact, the largest displacement vectors were visible under the right edges of the foundation, where some upward soil movements were also apparent. In Test $2 \mathrm{~s}$ (with air injection), the foundation settlement was slightly less $(21 \mathrm{~mm})$, and the extent of the displacement mechanism was slightly shallower. It appears that an extended bearing capacity mechanism was mobilised for both cases. For a comparison, the deformation mechanism developed 

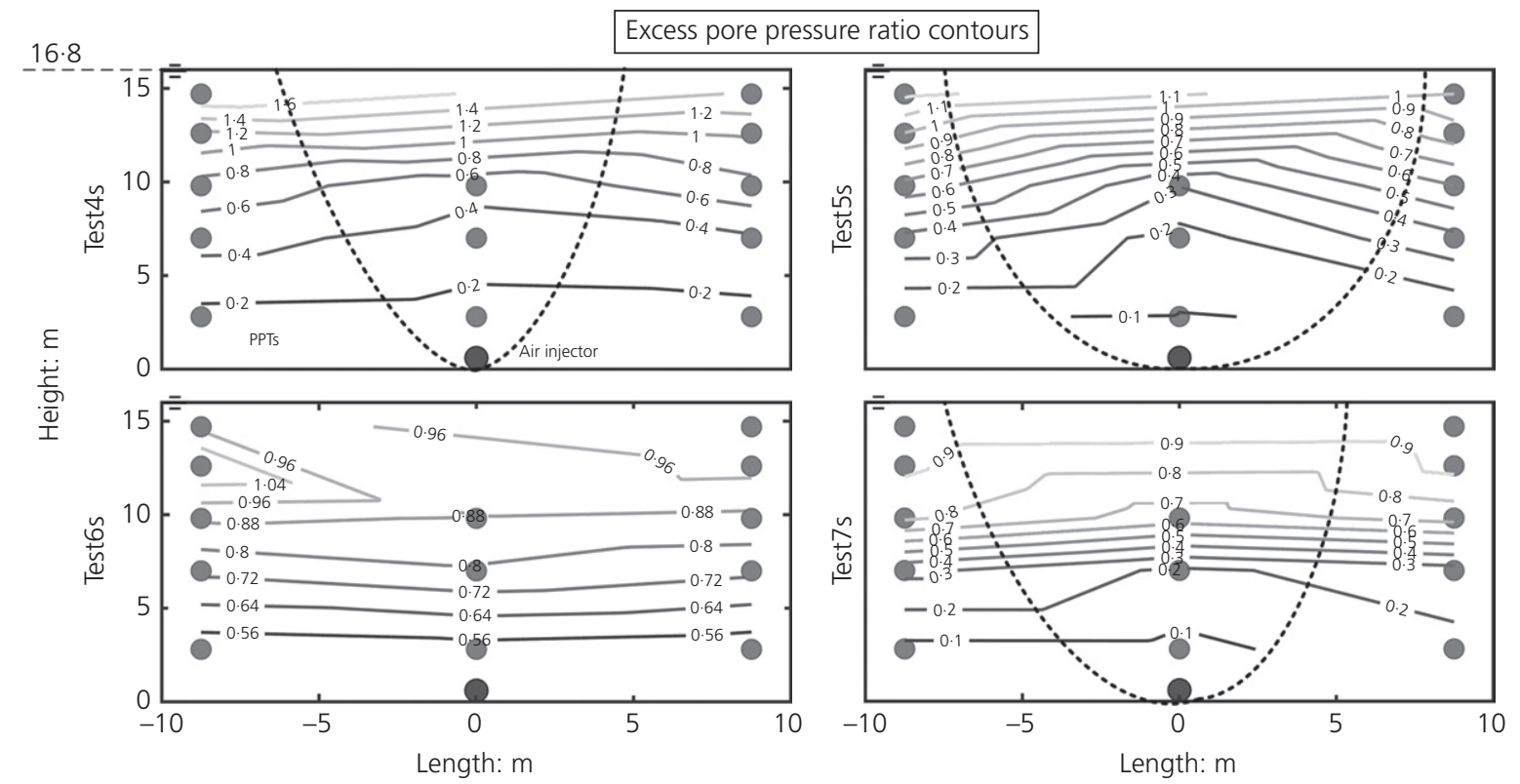

Figure 7. Variation of excess pore pressure ratios with distance from the air injector

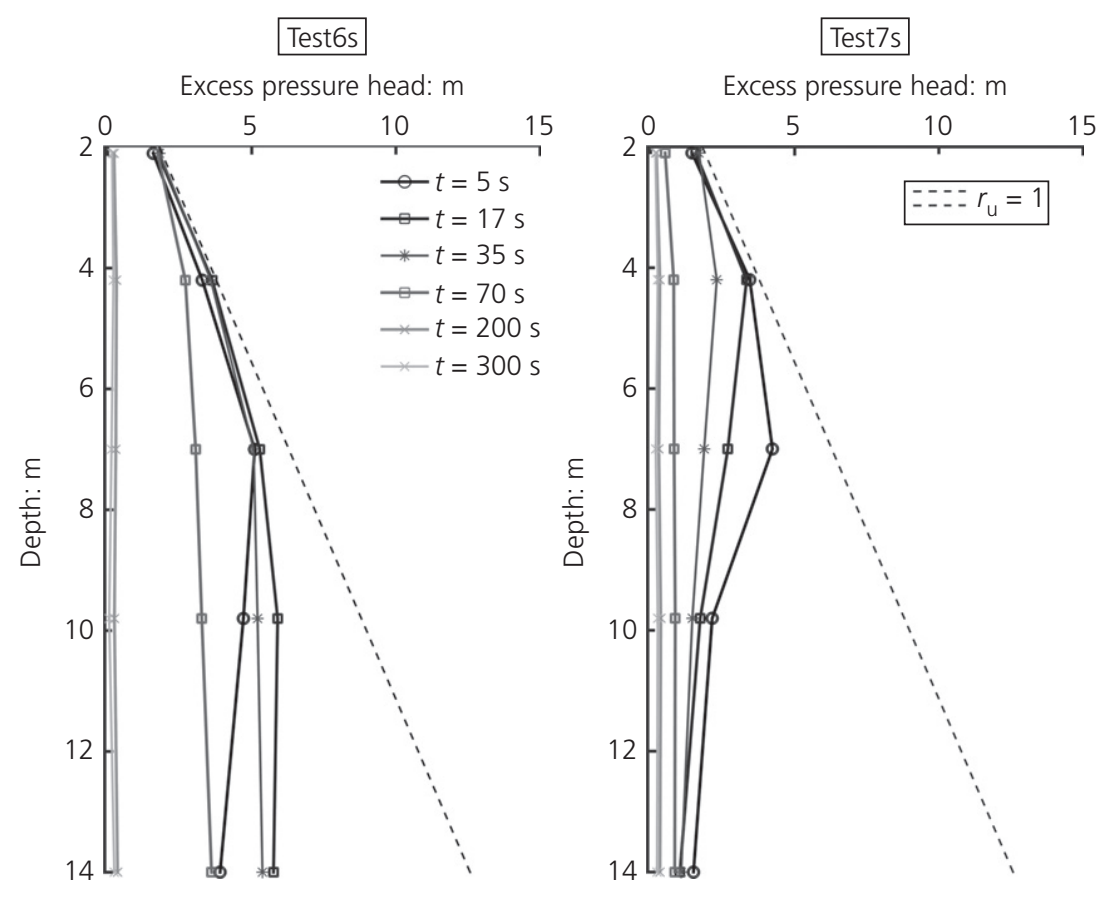

Figure 8. Variation of excess pore pressures with time and depth in the free field (Section 3)

during Test2c (improved with chemical compound) is explicitly shown in Figure 10. The comparison of the foundation settlements and excess pore pressures developed in all the tests is also depicted in this figure. As evident, the displacement mechanism observed in Test2c was very similar to Test $1 \mathrm{~s}$, and the foundation settlement was about $24 \mathrm{~mm}$. In the tests, injection of air or 

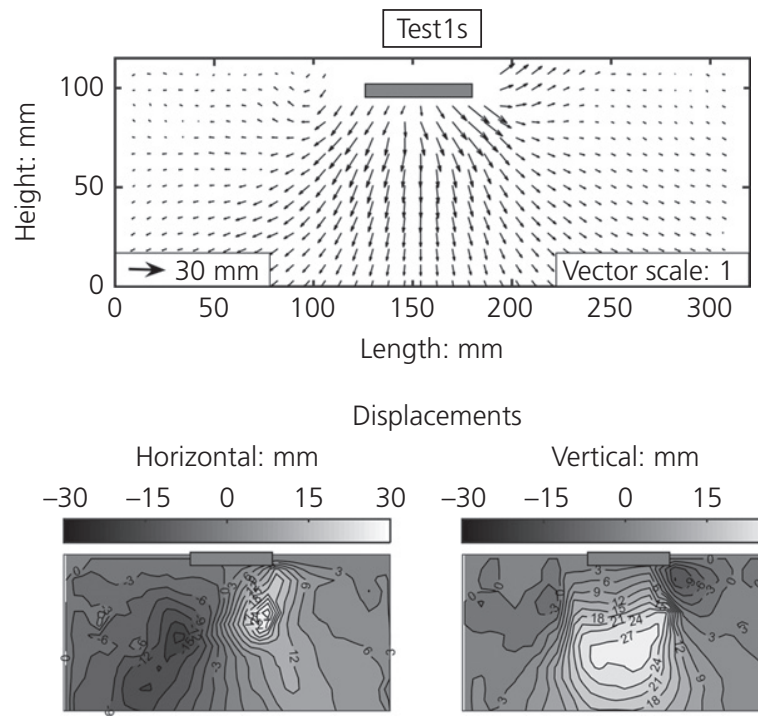

Displacements

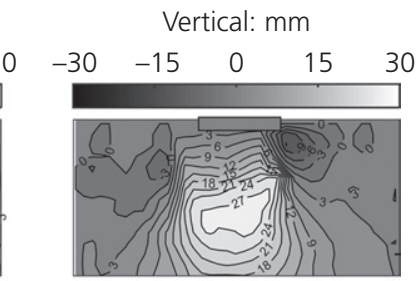

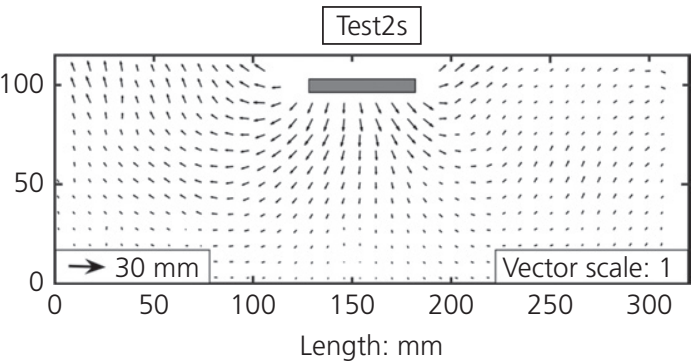

Displacements

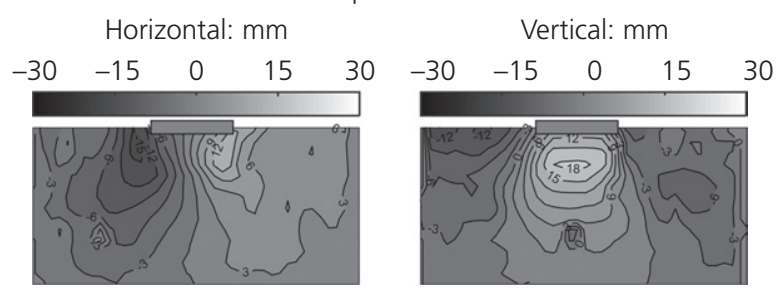

Figure 9. Accumulated soil displacements at $1 \boldsymbol{g}$ shaking table tests, calculated relative to the rigid base and corresponding to the whole duration of the seismic motion (MS)

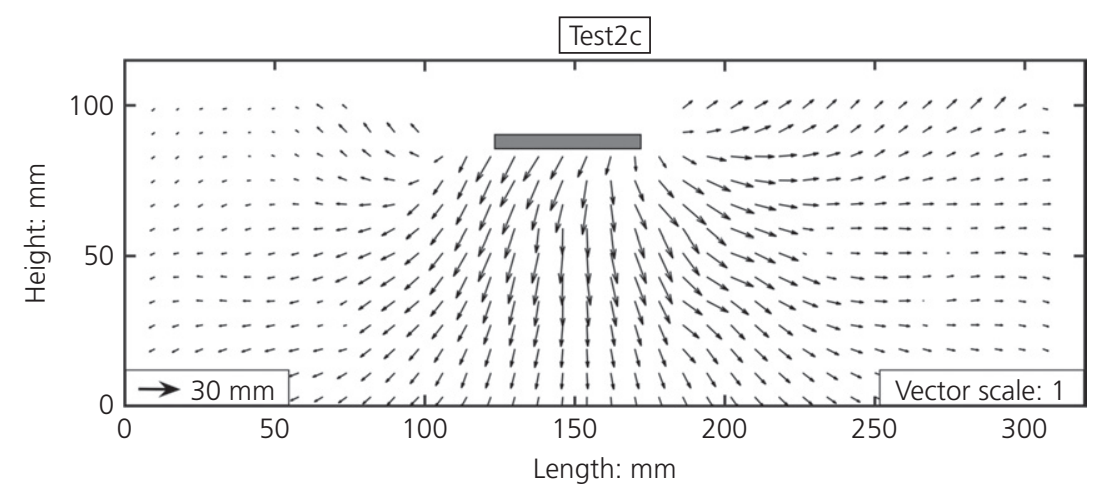

Figure 10. Accumulated soil displacements in Test2c, foundation settlements and excess pore pressures (EPP) recorded during the whole shaking table tests (MS)

using chemical compound caused only few per cent reduction in the magnitude of excess pore pressures generated at the middepth of the soil layer.

The stress level in soils at any depth is dependent on the selfweight of the overlaying soil deposit. The stress level
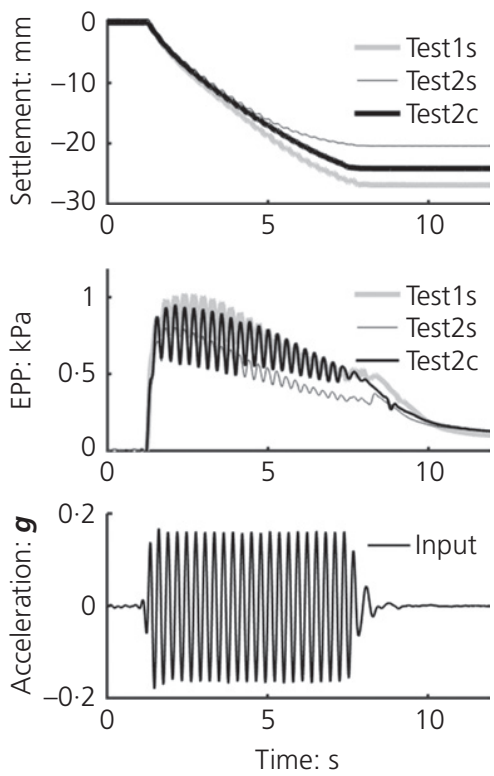


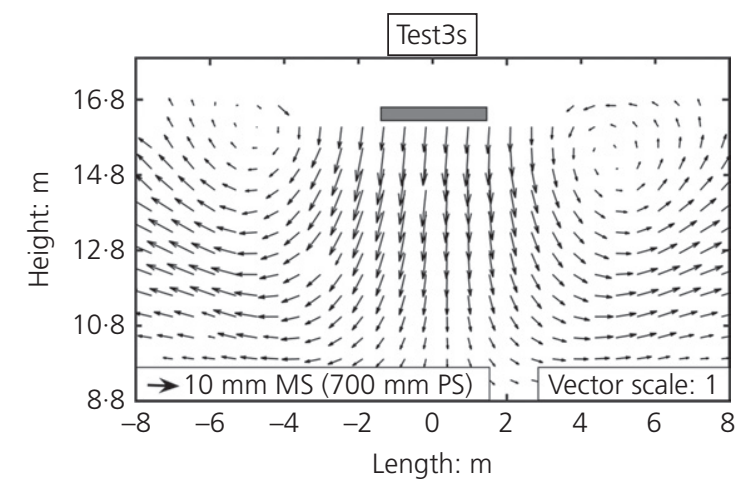

Horizontal displacement: $\mathrm{mm} \quad$ Vertical displacement: $\mathrm{mm}$

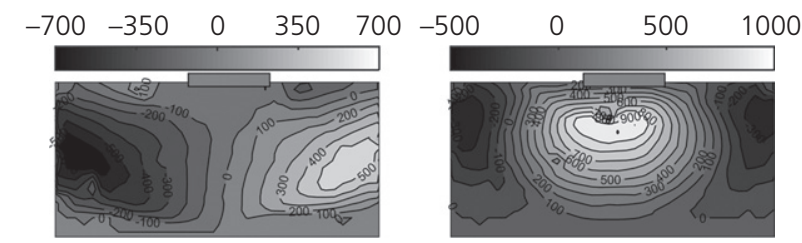

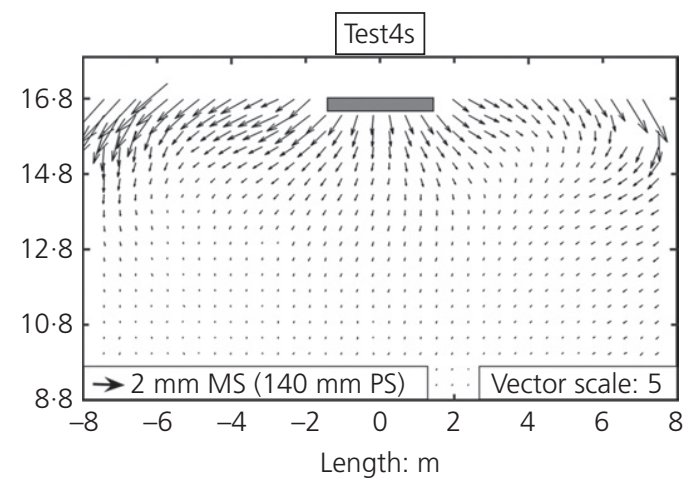

Horizontal displacement: $\mathrm{mm} \quad$ Vertical displacement: $\mathrm{mm}$

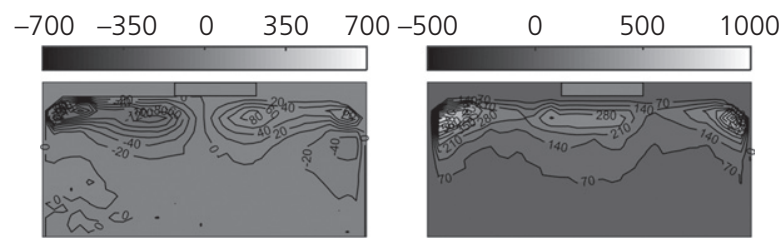

Figure 11. Accumulated soil displacements at $70 \mathrm{~g}$ centrifuge tests, calculated relative to the rigid base and corresponding to the whole duration of the seismic motion

of Test3s (with no air injection). An extended, bearing capacity mechanism was mobilised, and the foundation settled at $979 \mathrm{~mm}$ in the PS. On the other hand, a localised displacement mechanism at the shallow layers was present, and a mobilisation of bearing capacity mechanism did not appear in Test $4 \mathrm{~s}$. The settlement of foundation was recorded to be only $280 \mathrm{~mm}$ in the PS. The results of shaking table tests at $1 \boldsymbol{g}$ shows that air injection reduced the foundation settlement by only $22 \%$ when the initial $S_{\mathrm{r}}$ was reduced by more than $6 \%$. The soil specimens liquefied irrespective of the presence of air bubbles in the soil specimen. A similar behaviour was observed in the test with the chemical compound. However, during the centrifuge tests at $70 \mathrm{~g}$ the depth of liquefaction significantly reduced, and $6 \%$ reduction in $S_{\mathrm{r}}$ provided a $72 \%$ decrease in the average foundation settlement.

Figure 12 depicts the typical shear stress-strain histories calculated along the right hand side of the models (Section 3 in Figure 1) for the soil deposits with and without air injection. A one-dimensional vertical shear wave propagation within the soil columns was assumed. The shear stress and strain histories were calculated using the horizontal acceleration time histories recorded at different depths of the soil models and following the methodology proposed by Elgamal et al. (1996). In all cases, the initial small-strain shear stiffness appeared to increase with depth. The increase in the confining stress caused a corresponding increase in the soil's shear stiffness, which correlated well with many published data. In the nearly fully saturated soil (Test3s), the shallow and deeper soil layers liquefied after a few cycles, showing softened shear stressstrain $(\tau-\gamma)$ loops. In comparison, in the partially saturated soil (Test4s) the equivalent stress-strain loops demonstrated that while the soil at the shallow depth with lower confining stress behaved in a way similar to Test $3 \mathrm{~s}$, it showed significant shear stiffness at the deeper level. This might suggest that air injection enables the soil to resist full liquefaction at higher confining stresses, whereas it is less effective at lower confining stresses.

\section{Discussion of physical modelling of air injection}

The aforementioned results may suggest that the presence of air bubbles within the soil deposit has a smaller effect on its liquefaction resistance at lower confining stress. This finding is in accordance with the triaxial test data from Okamura and Soga (2006). Air injection is apparently insufficient at low stresses to minimise the liquefaction-induced deformations beneath shallow foundations and in the free field. Therefore, stress level should be carefully incorporated in the investigation of the air injection technique, particularly if the researchers are using $1 \mathrm{~g}$ shaking table apparatus.

The distribution of air bubbles trapped in soils was found to be non-uniform. Okamura and Noguchi (2009) stated that partially saturated soils with the uniformly distributed air bubbles 

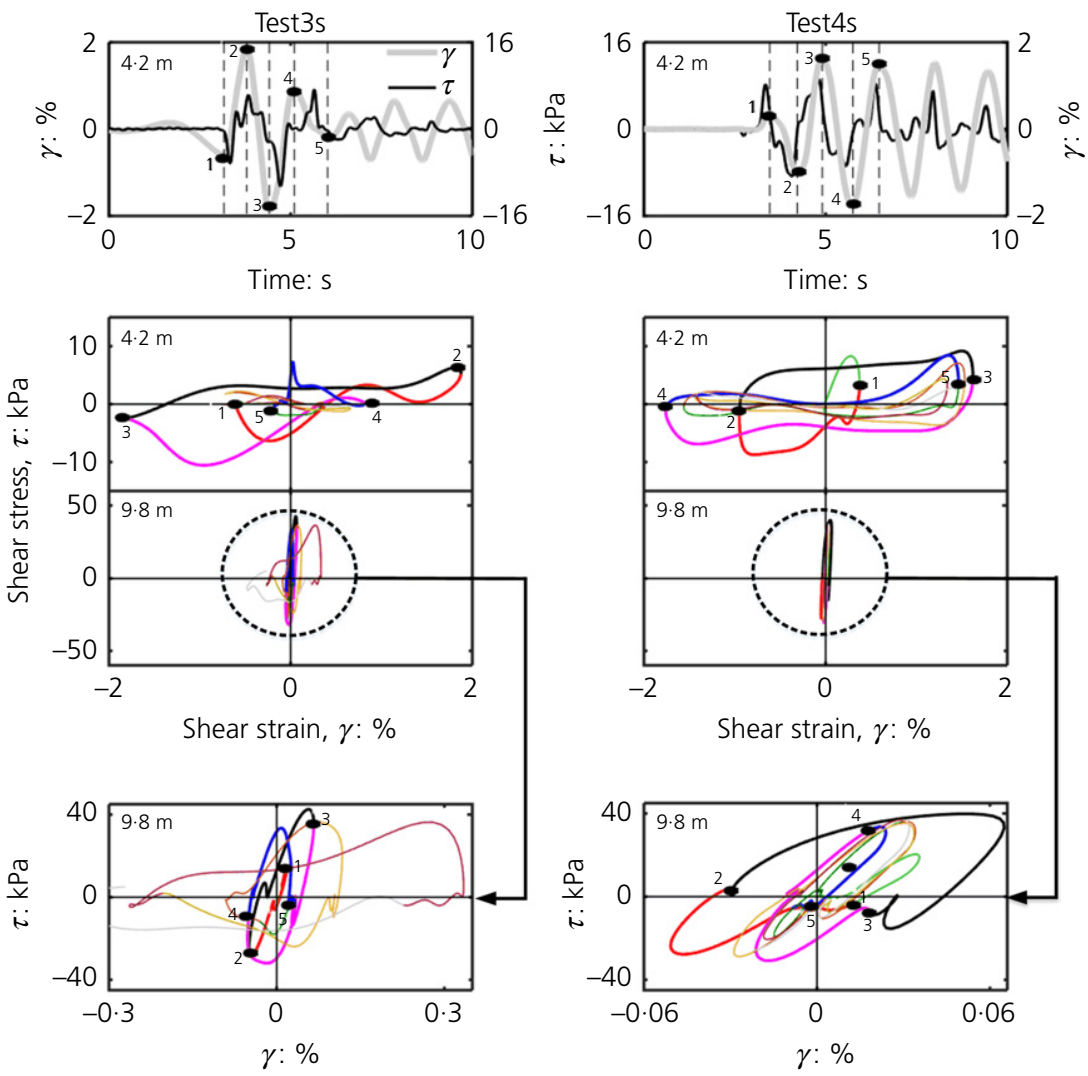

Figure 12. Shear stress-strain histories identified from the accelerations recorded at $70 \boldsymbol{g}$ centrifuge tests

would have the same liquefaction resistance as the soils with the heterogeneously distributed air bubbles if sufficient time was allowed for the pore water to flow towards the air bubbles. However, it was difficult to verify this finding herein. The liquefaction resistance of soils (in terms of excess pore pressure generation) varied at discrete points of soil due to the non-uniformity of desaturation. It is thought that the migration of the pore fluid from saturated to partially saturated zone is difficult. The air in a trapped bubble will be compressible. However, if the bubble is compressed it will increase its air pressure according to Boyle's gas law. Therefore, it cannot be like a drainage boundary. Moreover, pore fluid flow will be very difficult since the bubbles act as a blockage and decrease the hydraulic conductivity of the soils. Therefore, the distribution of air bubbles should be also taken into account.

\section{Conclusions}

Air injection technique can be an easy and cheap solution for liquefaction problems. However, to the authors' knowledge so far only few researchers have devoted their efforts to this particular technique. Therefore, effective guidelines that can be reliably utilised in practice still remain elusive. The objective of this paper was to offer novel insights into the effective use of air injection technique and investigate the associated important parameters. Of particular interest was the way that the successful application and performance of air injection technique beneath the existing structures with shallow foundations requires a wellcontrolled process and consideration of the key parameters: air distribution and confining stress. Eight centrifuge and three shaking table tests were presented for this purpose.

Considering the results presented herein, it was obvious that during the application of air injection the settlement of the shallow foundation of an existing structure may be inevitable due to the increased compressibility of pore fluid within the soil and airflow-induced deformations. However, the magnitude of this settlement can be reduced to the acceptable limits if the applied net air injection pressure is kept smaller, and air pressure is increased in a controlled manner. On the other hand, the air pressure applied was also found to have some implications on the distribution, magnitude of desaturation and, therefore, on the seismic response of air-injected partially saturated soils. Lower air injection pressures resulted in great heterogeneity within the air-entrapped zone, causing the liquefaction resistance to vary across it. Moreover, with the smaller air pressure it was difficult to lower the degree of saturation 
of soil to the targeted level, when a lower value was aimed. The desaturated zone apparently did extend laterally, but to a certain degree. Therefore, the zone of influence remained very limited in the event of lower air pressure applied.

The efficacy and validity of the air injection technique to reduce the liquefaction-induced deformations beneath shallow foundations was investigated at different confining stresses, using a suit of centrifuge and $1 \boldsymbol{g}$ shaking table tests. It was shown that this technique is less effective at low confining stresses. An extended bearing capacity mechanism was mobilised in all $1 \mathrm{~g}$ tests, irrespective of the presence of bubbles. However, in centrifuge tests at $70 \mathrm{~g}$ the inclusion of air bubbles into the saturated soil reduced the depth of liquefaction and prevented the formation of bearing capacity deformation mechanism. In this light, it is recommended that stress level is a parameter to be considered in the practice.

This paper offers useful insights into the air injection technique. However, further analysis is essential to determine the other key parameters that affect the performance of this technique and their intricate interplay. This could be an important step towards realising effective design guidelines for practising engineers.

\section{Acknowledgements}

The centrifuge experiments were performed with the excellent help of the technicians at the Schofield Centre of Cambridge University. This support is acknowledged. The first author extends his thanks to the Ministry of National Education (MEB) of Turkey for their financial support.

\section{REFERENCES}

Elgamal AW, Zeghal M and Parra E (1996) Liquefaction of reclaimed island in Kobe, Japan. Journal of Geotechnical Engineering 122(1): 39-49.

Gokyer S (2009) Inducing and Imaging Partial Degree of Saturation in Laboratory Sand Specimens. MS thesis, Northeastern University, Boston, MA, USA.

Madabhushi SPG, Schofield AN and Lesley S (1998) A new stored angular momentum (SAM) based earthquake actuator. In Proceedings of Centrifuge '98, Tokyo, Japan (Kimura T, Kusakabe $\mathrm{O}$ and Takemura J (eds)). Balkema, Rotterdam, the Netherlands, vol. 1, pp. 111-116.

Ogata $\mathrm{H}$ and Okamura M (2006) Experimental study on air behavior in saturated soil under air injection. Proceedings of the Symposium on Natural Disaster Prevention. Japan Society of Civil Engineers (JSCE), Tokushima, Japan, pp. 89-90.

Okamura M and Noguchi K (2009) Liquefaction resistance of unsaturated non-plastic silt. Soils and Foundations 49(2): 221-229.

Okamura M and Soga Y (2006) Effects of pore fluid compressibility on liquefaction resistance of partially saturated sand. Soils and Foundations 46(5): 695-700

Okamura M and Tomida Y (2015) Full scale test on cost effective liquefaction countermeasure for highway embankment. Proceedings of Sixth International Geotechnical Symposium on
Disaster Mitigation in Special Geoenvironment Conditions. IIT Madras, Chennai, India, pp. 208-212.

Okamura M, Ishihara M and Tamura K (2006) Degree of saturation and liquefaction resistances of sand improved with sand compaction pile. Journal of Geotechnical and Geoenvironmental Engineering ASCE 132(2): 258-264.

Okamura M, Takebayashi M, Nishida K et al. (2011) In-situ desaturation test by air injection and its evaluation through field monitoring and multiphase flow simulation. Journal of Geotechnical and Geoenvironmental Engineering ASCE 137(7): 643-652.

Schofield AN (1981) Dynamic and earthquake geotechnical centrifuge modelling. Proceedings of International Conference on Recent Advances in Geotechnical Earthquake Engineering and Soil Dynamics. University of Missouri, Rolla, MO, USA, pp. 1081-1100.

Seed RB, Cetin KO, Moss RES et al. (2003) Recent advances in soil liquefaction engineering: a unified and consistent framework. Proceedings of 26th Annual Los Angeles Geotechnical Spring Seminar. American Society of Civil Engineers (ASCE), Long Beach, CA, USA, pp. 301-371.

Steedman RS and Madabhushi SPG (1991) Wave propagation in sand medium. Proceedings of Fourth International Conference on Seismic Zonation. Stanford University, Palo Alto, CA, USA, pp. 253-260.

White DJ, Take WA and Bolton MD (2003) Soil deformation measurement using particle image velocimetry (PIV) and photogrammetry. Géotechnique 53(7): 619-631, https://doi.org/ 10.1680/geot.2003.53.7.619.

Yasuhara H, Kochi M and Okamura M (2008) Experiments and predictions of soil desaturation by air injection technique and the implications mediated by multiphase flow simulation. Soils and Foundations 48(6): 791-804.

Yegian MK, Eseller-Bayat E, Alshawabkeh A and Ali S (2007) Induced-partial saturation for liquefaction mitigation: experimental investigation. Journal of Geotechnical and Geoenvironmental Engineering ASCE 133(4): 372-380.

Zeybek A and Madabhushi SPG (2017a) Centrifuge testing to evaluate the liquefaction response of air-injected partially saturated soils beneath shallow foundations. Bulletin of Earthquake Engineering 15(1): 339-356.

Zeybek A and Madabhushi SPG (2017b) Influence of air injection on the liquefaction-induced deformation mechanisms beneath shallow foundations. Soil Dynamics and Earthquake Engineering 97: 266-276.

\section{How can you contribute?}

To discuss this paper, please email up to 500 words to the editor at journals@ice.org.uk. Your contribution will be forwarded to the author(s) for a reply and, if considered appropriate by the editorial board, it will be published as discussion in a future issue of the journal.

International Journal of Physical Modelling in Geotechnics relies entirely on contributions from the civil engineering profession (and allied disciplines). Information about how to submit your paper online is available at www. icevirtuallibrary.com/page/authors, where you will also find detailed author guidelines. 